\title{
IMPROVING RADIOGRAPHER UNDERSTANDING OF DIAGNOSTIC REFERENCE LEVEL AS AN EFFORT TO OPTIMIZE RADIOGRAPHIC EXAMINATION
}

$\begin{array}{llll}\text { PENINGKATAN } & \text { PEMAHAMAN RADIOGRAFER TERHADAP DIAGNOSTIC } \\ \text { REFERENCE } & \text { LEVEL SEBAGAI UPAYA OPTIMISASI PEMERIKSAAN } \\ \text { RADIOGRAFI } & & & \end{array}$

Muhammad Irsal $^{1 *}$, Mayarani², Bambang Suroso ${ }^{3}$, Muhammad Ichsan $^{4}$, Andri Yansyah $^{5}$

\begin{abstract}
Radiographers are responsible for producing good image quality by providing the lowest possible radiation dose, by the As Low As Reasonably Achievable (ALARA) principle. One of the ALARA principle methods in a radiographic examination is to implement optimization efforts by knowing the $\mathrm{DRL}$. The research method is a quantitative description using the measurement method radiation output as a way for radiographers to estimate the radiation dose received by patients, then socialization to 17 radiographers about DRL as an effort to optimize radiographic examinations using the results of percentage pre and post-test as indicators of success $>90 \%$, with conclusions about the increase in radiographers' understanding of DRL as an effort to optimize the value paired t-test $p<0,05$. The results of the radiation dose estimation using the method radiation output by determining the equation power function $y=0,0005 \mathrm{x}^{2.9242}$. From the results, the pre-test found the number of correct answers with a percentage of $59 \%$. While for the results of the post-test number of correct answers that percentage is $94 \%$. The results of the test to increase the understanding of the radiographer as an optimization effort based on the statistical test paired t-test $p$-value $<0,001$ So it is certain that radiographers have increased understanding after socialization about DRL as an effort to optimize the radiographic examination.
\end{abstract}

Keywords: DRL Socialization, Optimization Efforts, Radiographer's Understanding

\section{INTISARI}

Radiografer bertanggung jawab dalam menghasilkan kualitas citra yang baik dengan pemberian dosis radiasi serendah mungkin, sesuai dengan prinsip As Low As Reasonably Achieveable (ALARA) . salah satu metode prinsip ALARA dalam pemeriksaan radiografi ada dengan menerapkan upaya optimisasi dengan mengetahui DRL. Metode penelitian bersifat deskripsi kuantitatif dengan menggunakan metode pengukuran radiation output sebagai salah satu cara radiografer dalam estimasi dosis radiasi yang diterima pasien, kemudian sosialisasi kepada 17 orang radiografer tentang DRL sebagai upaya optimisasi dalam pemeriksaan radiografi dengan menggunakan hasil presentase pre dan post-test sebagai indikator keberhasilan $>90 \%$, dengan pengambilan

Afiliasi Penulis

Poltekkes Kemenkes Jakarta II

\section{Korespondensi kepada}

Muhammad Irsal

muhammad.irsal@poltekkesjkt2.ac.id kesimpulan tentang peningkatan pemahaman radiografer terhadap DRL sebagai upaya optimisasi apabila nilai paired t-test $p$-value $<0,05$. Hasil estimasi dosis radiasi menggunakan metode radiation output dengan menentukan persamaan power function $\mathrm{y}=0.0005 \mathrm{x}^{2.9242}$. Dari hasil pre-test didapatkan jumlah jawaban yang benar dengan presentase yaitu 59\%. sedangkan untuk hasil 
post-test jumlah jawaban yang benar yaitu presentase yaitu $94 \%$. Hasil uji peningkatan pemahaman radiografer sebagai upaya optimisasi berdasarkan uji statistik paired $t$-test $p$-value $<0,001$. Maka dipastikan radiografer mengalami peningkatan pemahaman setelah dilakukan sosialisasi tentang DRL sebagai upaya optimisasi pada pemeriksaan radiografi.

Kata kunci: Pemahaman Radiografer, Sosialisasi DRL, Upaya Optimisasi.

\section{PENDAHULUAN}

Penggunaan Sinar-X tidak terlepas dari dampak yang ditimbulkan selain manfaat yang begitu besar dalam bidang kesehatan terutama dalam radiologi diagnostik. Jika sinar-X diberikan pada tubuh pada saat pemeriksaan radiografi, kulit akan menerima paparan radiasi paling besar. Dalam pencitraan medis pengukuran paparan radiasi dikenal dengan istilah entrance surface air kerma (ESAK) yaitu pengukuran paparan radiasi pada pusat penyinaran sinar-X (IAEA, 2007) (Nations Scientific Committee on the Effects of Atomic Radiation, 2010). Salah satu metode pengukuran ESAK dengan menentukan radiaion output dari pesawat sinar- $\mathrm{X}$ (Hiswara \& Kartikasari, 2015) (Muhammad, Hidayanto, \& Arifin, 2014).

Dosis pasien ditentukan oleh beberapa parameter sinar X seperti kV, mAs, Grid, SID, filter, kolimasi berkas (Don, Whiting, Rutz, \& Apgar, 2012). Berdasarkan IAEA-TECDOC1423 menunjukkan bahwa program jaminan mutu memberikan dampak positif dalam setiap tindakan pemeriksaan radiografi, Sesuai dengan hal tersebut maka apabila kinerja pesawat sinar- $X$ tidak sesuai dengan hasil jaminan mutu, maka akan memberikan dampak negatif bagi pasien dan berpotensi memberikan tambahan dosis yang tidak perlukan (Hastuti, Syafitri, Di, Radiologi, \& Definisi, 2009).

Pada pemeriksaan radiografi paparan radiasi yang diberikan kepada pasien harus diupayakan sesuai dengan proteksi radiasi yang terdiri dari prinsip justifikasi, optimisasi dan limitiasi. Dimana salah satu upaya yang dapat dilakukan oleh radiografer dengan pertimbangan tingkat referensi diagnostik (Diagnostic Reference Levels) (BAPETEN, 2019), oleh karena itu, tujuan pemeriksaan radiografi dapat dilakukan dengan hasil citra yang mampu memberikan informasi diagnosa yang diperlukan dengan mengoptimalkan paparan radiasi diberikan kepada pasien. hal ini berhubungan dengan jaminan mutu pesawat sinar-X (Muhammad et al., 2014).

Dosis pasien pemeriksaan radiologi ditentukan oleh radiografer dengan mempertimbangkan agar pemberian dosis pasien serendah mugkin (As Low As Reasonably Achievable - ALARA), dengan tidak mengurangi kualitas pencitraan radiografi yang dihasilkan (Irsal, 2020). Salah satu prinsip proteksi radiasi yang bisa diaplikasikan dalam pemeriksaan radiografi yaitu optimisasi, dimana pemberian dosis radiasi diupaya sosial dan ekonomi, untuk indonesia pemeriksaan radiografi tentang keselamatan dalam penggunaan pesawat sinar-X diatur dalam peraturan kepala BAPETEN (BAPETEN, 2011) (BAPETEN, 2003).

Tujuan Diagnostic Reference Level (DRL) digunakan sebagai alat optimisasi dalam melakukan upaya proteksi radiasi kepada pasien, dengan mencegah paparan radiasi yang tidak diperlukan. Upaya 
optimisasi merupakan proses untuk menuju optimal yaitu proses berkelenjutan secara terus menerus dengan mengupayakan pemberian dosis serendah mungkin dengan meningkatkan kualitas citra dalam mendiagnosa penyakit. (BAPETEN, 2016) (BAPETEN, 2002). Dalam praktik klinis radiografer sering kali memiliki kendala dalam melakukan upaya optimisasi, hal ini terkait dengan setiap pemeriksaan radiografi selalu mengupayakan dosis radiasi yang optimal kepada pasien dimana pasien dan radiografer , serta pengalaman klinis radiografer dalam penerapan penerapan prinsip ALARA, sehingga diperlukan sosialisasi pemahaman radiografer terhadap diagnostic reference level sebagai upaya optimisasi pemeriksaan radiografi.

\section{METODE}

Metode penelitian bersifat deskripsi kuantitatif dengan melakukan peningkatan pemahaman radiografer terhadap diagnostic reference level sebagai upaya optimisasi pemeriksaan radiografi dengan pemberian sosialisasi tentang panduan DRL pesawat sinar-X di RSUD Tarakan DKI Jakarta. Metode dengan melakukan pengukuran radiation output sebagai referensi dalam estimasi dosis radiasi yang diterima pasien, sehingga radiografer dapat menggunakan sebagai panduan mengetahui dosis radiasi yang diterima pasien. Kemudian dilakukan sosialisasi untuk mengukur tingkat pemahaman radiografrer tentang DRL, analisa data dilakukan dengan data pre dan post-testkepada 17 orang radiografer, dengan pemberian materi tentang $D R L$ terkait dengan penjelasan paparan medik, prinsip ALARA yang digunakan dalam praktik radiografi dan penjelasan terhadap aturan terkait DRL. kemudian dibuat presentase hasil pre dan post-test sebagai indikator keberhasilan, dengan pengambilan kesimpulan tentang peningkatan pemahaman radiografer terhadap DRL sebagai upaya optimisasi apabila nilai paired $t$-test $p<0,05$.

\section{HASIL DAN PEMBAHASAN}

1. Pengukuran radiation output sebagai referensi estimasi dosis radiasi yang diterima pasien

Tingkat paparan medik atau disebut dengan DRL direkomendasikan sebagai panduan dalam melakukan pemeriksaan radiografi sebagai parameter penentuan dosis radiasi dan kualitas citra yang digunakan oleh dokter, radiografer dan fisikawan medik. Hal ini bertujuan agar radiografer dan pasien dapat mengetahui dosis radiasi yang pada saat melakukan pemeriksaan radiografi, oleh karena itu untuk mendapatkan informasi dosis radiasi dilakukan pengukuran estimasi dosis radiasi menggunakan metode radiation output dengan pengukuran menggunakan detektor radiasi. Pengukuran dilakukan di instalasi radiologi RSUD Tarakan DKI Jakarta. Kondisi pesawat sinar-X sudah dilakukan uji kesesuaian dan telah mendapatkan izin opersional dari BAPETEN, dengan spesifikasi sebagai berikut :

\section{Tabel 1 | Spesifikasi pesawat sinar-X}

\begin{tabular}{ll}
\hline & \multicolumn{1}{c}{ Pesawat sinar-X } \\
\hline Nama & Siemens Multipurpose OPTITOP 150/40/80HC-100 \\
\hline Merk & Siemens \\
\hline Tipe & 03345209 \\
\hline Seri & 403161552 \\
\hline
\end{tabular}




\begin{tabular}{ll}
\hline Tabung & OPTITOP 150/40/80HC-100 \\
\hline Focal spot & $0,6 / 1,0$ \\
\hline Total Filter & $1,5 \mathrm{~mm} \mathrm{Al} / 75 \mathrm{kVp}$ \\
\hline Kapasitas & $150 \mathrm{kV}$ \\
\hline & $640 \mathrm{mAs}$ \\
\hline
\end{tabular}

Rekomendasi IAEA pada TRS 457 yang kemudian menjadi rujukan BAPETEN tentang DRL menjelaskan tentang metode pengukuran secara langsung dan pengukuran secara tidak langsung, salah satu pengukuran secara tidak langsung menggunakan metode radiation output disertai dengan perhitungan backscatter. Pengukuran dimulai dengan penentuan incident air kerma yaitu pengukuran dosis radiasi tanpa menggunakan detektor radiasi ditunjukan pada gambar 2 ,

Tabel 2 | Pengukuran Incident Air Kerma luas lapangan $25 \mathrm{~cm}^{2}$ dengan arah berkas penyinaran tegak lurus dengan tabung sinar- $X$ pada jarak $100 \mathrm{~cm}$, pengukuran incident air kerma menggunakan beberapa parameter variasi tegangan tabung $60 \mathrm{kV}, 70 \mathrm{kV}, 81 \mathrm{kV}$, $90 \mathrm{kV}, 100 \mathrm{kV}, 113 \mathrm{kV}, 121 \mathrm{kV}$ dan waktu paparan $10 \mathrm{mAs}$, pengukuran ini dilakukan sebanyak $3 x$ untuk satu kali perubahan nilai kV. kemudian hasilnya dicatat seperti ditunjukan pada Tabel 2.

\begin{tabular}{cccc}
\hline $\begin{array}{c}\text { Tegangan tabung } \\
(\mathbf{k V p})\end{array}$ & $\begin{array}{c}\text { Standar } \\
\text { deviasi } \mathbf{~ k \mathbf { p }}\end{array}$ & $\begin{array}{c}\text { Keluaran pada } \\
\mathbf{1 0 0} \mathbf{~} \mathbf{m}(\boldsymbol{\mu G} / \mathbf{m A s})\end{array}$ & $\begin{array}{c}\text { Standar deviasi } \\
\boldsymbol{\mu} \mathbf{G y} / \mathbf{m A s}\end{array}$ \\
\hline $\mathbf{6 0}$ & 0,115 & 80,78 & 0,301 \\
\hline $\mathbf{7 0}$ & 0,208 & 134,8 & 0,000 \\
\hline $\mathbf{8 1}$ & 0,264 & 213,63 & 0,305 \\
\hline $\mathbf{9 0}$ & 0,208 & 290,83 & 0,450 \\
\hline $\mathbf{1 0 0}$ & 0,005 & 389,53 & 0,723 \\
\hline $\mathbf{1 1 3}$ & 0,450 & 533,67 & 0,378 \\
\hline $\mathbf{1 2 1}$ & 0,264 & 631,5 & 0,824 \\
\hline
\end{tabular}




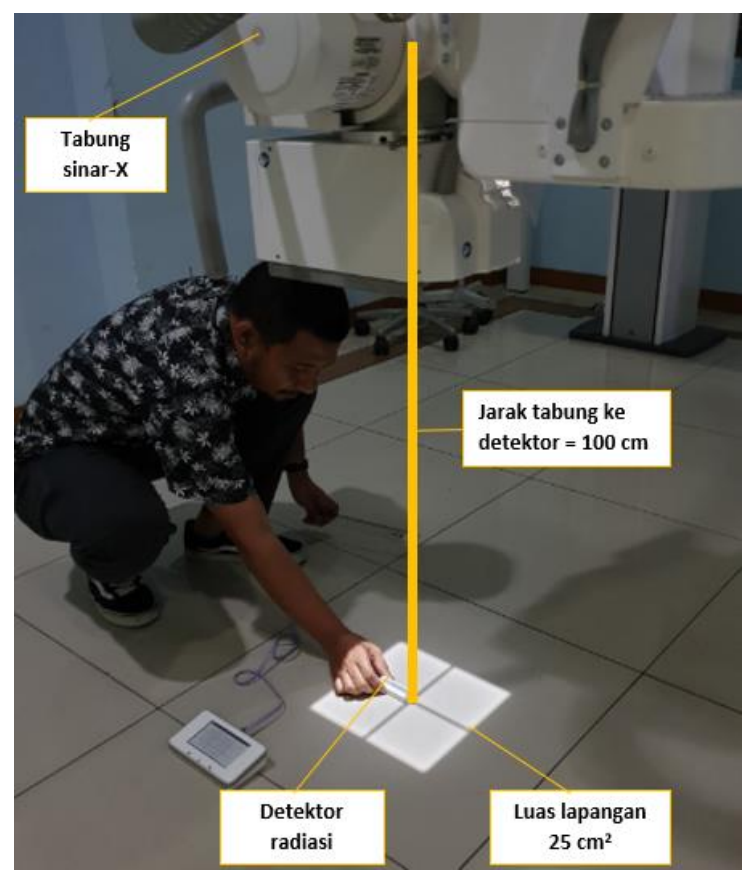

Gambar 1 | Pengukuran Keluaran Radiasi

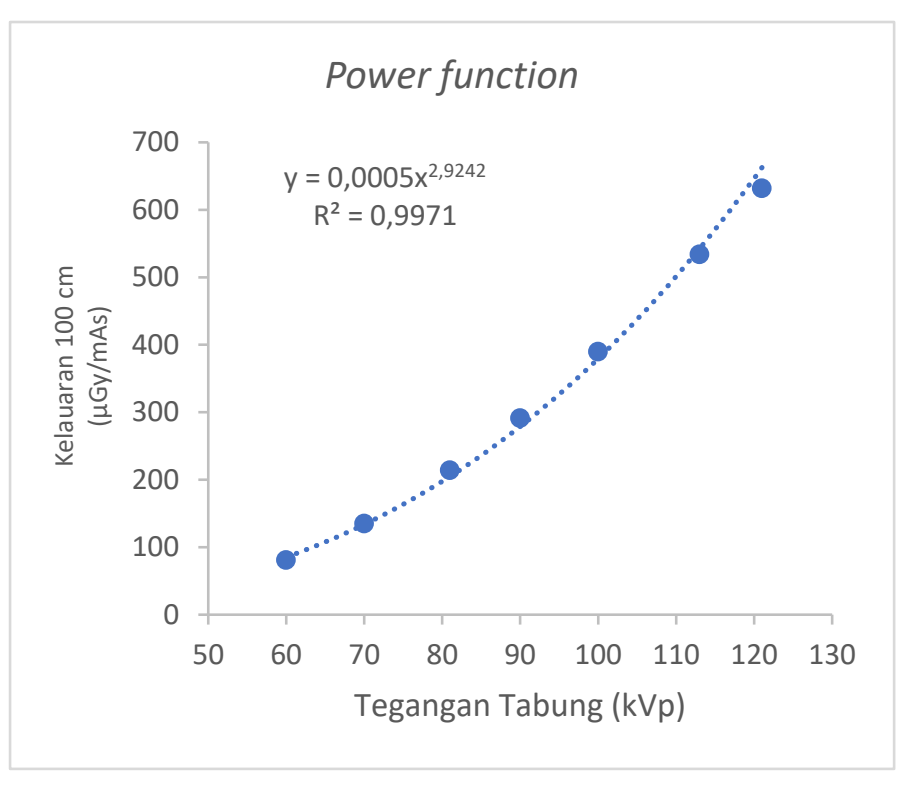

Gambar 2 | Grafik Persamaan Power Function

Kemudian hasil bacaan pada detektor radiasi dibuat dalam tabel dan dianalisa menggunakan persamaan power function dengan memberikan nilai data hasil pengukuran radiation output, dimana nilai laju dosis radiasi meningkat seiring meingkatnya 
nilai kVp yang ditunjukan pada Gambar 3 . Dalam estimasi dosis radiasi dengan menggunakan power function :

$$
y=0,0005 x^{2,9242}
$$

Sehingga berdasarkan persamaan :

$$
\text { Dosis Radiasi ( } \mu \mathrm{Gy})=\mathrm{B} \text { x Kerma }
$$

(BAPETEN, 2016)

$$
\text { Kerma }=0,0005 \times \mathrm{kV}^{2,9242} \times \mathrm{mAs} \times\left(\frac{\mathrm{FD}}{\mathrm{FFD}}\right)^{2}
$$

(BAPETEN, 2016)

Dosis Radiasi : ESD atau entrance surface air kerma ( $\mu \mathrm{Gy})$

B : Backscatter factor
$K_{\text {erma }}$ : Dosis insiden atau incident air kerma ( $\mu \mathrm{Gy})$

kV : Tegangan tabung

mAs : Arus tabung

$F D$ : Jarak fokus ke detektor

$F F D$ : Jarak fokus ke kaset radiografi

Diasumsikan pada pemeriksaan radiografi paru-paru menggunakan kondisi penyinaran $60 \mathrm{kV}, 5 \mathrm{mAs}$ dengan jarak fokus ke kaset radiografi $150 \mathrm{~cm}$, dosis radiasi yang diterima yaitu, diketahui:

$$
\begin{aligned}
& \mathrm{kV}=60 \\
& \mathrm{mAs}=5 \\
& \mathrm{FFD}=150 \mathrm{~cm} \\
& \mathrm{FD}=100 \mathrm{~cm} \\
& \text { Kerma }=\mathbf{0}, \mathbf{0 0 0 5} \times \mathbf{6 0}^{\mathbf{2 , 9 2 4 2}} \times \mathbf{5} \times\left(\frac{\mathbf{1 0 0}}{\mathbf{1 5 0}}\right)^{2} \\
&=\mathbf{1 , 7 6} \boldsymbol{\mu G y}
\end{aligned}
$$

Tabel 3 | Backscatter

\begin{tabular}{cc}
\hline $\mathbf{k V}$ & Tissue air $^{*}$ (backscatter) $\mathbf{2 5} \mathbf{~ c m}^{\mathbf{2}}$ \\
\hline $\mathbf{5 0}$ & 1,28 \\
\hline $\mathbf{6 0}$ & 1,32 \\
\hline $\mathbf{7 0}$ & 1,38 \\
\hline $\mathbf{8 0}$ & 1,41 \\
\hline $\mathbf{9 0}$ & 1,44 \\
\hline $\mathbf{1 0 0}$ & 1,55 \\
\hline $\mathbf{1 2 0}$ & 1,49 \\
\hline $\mathbf{1 3 0}$ & 1,56 \\
\hline $\mathbf{1 5 0}$ & 1,57 \\
\hline${ }^{*}$ Technical Report Series No 457; Dosimetry in Diagnostic \\
Radiology: An International Code of Practice \\
\hline
\end{tabular}

Untuk mengetahui estimasi nilai dosis yang diterima dengan memperhatikan nilai backscatter pada Tabel 2, dikarenakan pada prinsipnya hasil pengukuran menggunakan detektor radiasi hanya dapat mengukur jumlah radiasi primer tanpa memperhitungkan radiasi backscatter, sedangkan untuk pengukuran ESD membutuhkan nilai backscatter.
Sehingga untuk penggunaan kV 60 maka nilai backscatter adalah 1.32. dengan contoh perhitungan nilai ESD sebagai berikut :

$$
\text { Dosis Radiasi }(\mu \mathrm{Gy})=1,32 \times 1.76 \mu \mathrm{Gy}
$$

$$
=2,32 \mu \mathrm{Gy}
$$


2. Peningkatan pemahaman radiografer tentang DRL sebagai upaya optimasi dalam pemeriksaan radiografi

Sosialisasi pemahaman tentang DRL dengan melakukan analisa presentase pre dan post-test, hal ini bertujuan agar dalam melaksanakan pemeriksaan radiografi dapat memahami konsep optimisasi pada pemeriksaan radiografi dan diaplikasikan kepada pasien. Kegiatan ini dilakukan secara langsung dengan melakukan sosialisasi penjelasan materi dan tanya jawab. Kegiatan dimulai dengan melakukan pre-test tentang pemahaman terhadap DRL dengan soal pretest berjumlah 12 soal, dilakukan kepada radiografer dengan jumlah responden 17 orang. Setelah itu diberikan materi tentang DRL terkait dengan penjelasan paparan medik, prinsip ALARA yang digunakan dalam praktik radiografi dan penjelasan terhadap aturan terkait DRL. Kemudian sebagai pengukuran pemahaman sosialisasi dengan melaksanakan post-test, dengan harapan penilaian presentase setelah penjelasan materi nilai post test $>90 \%$.

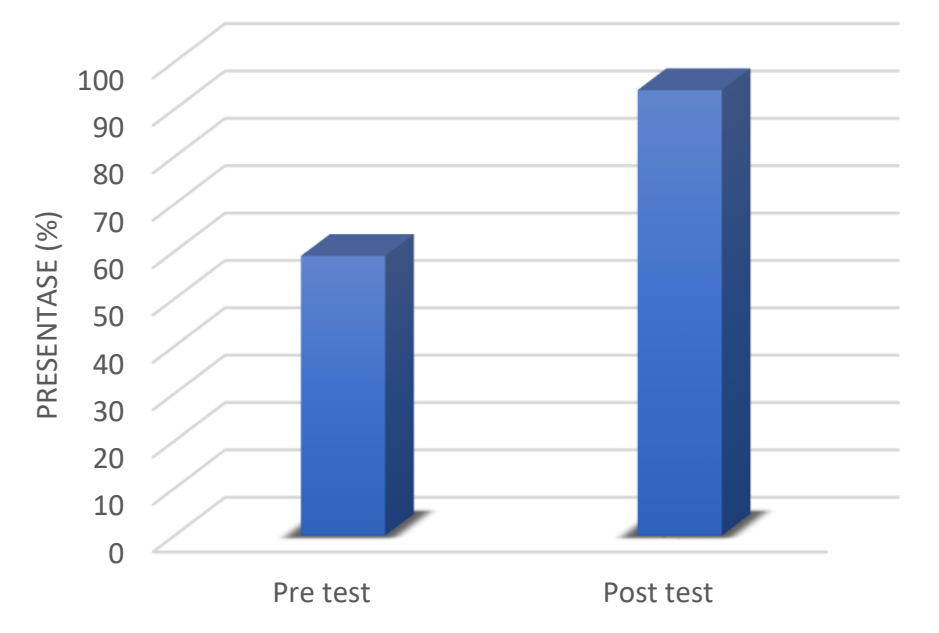

Gambar 3 | Presentase pre dan post-test

Tabel 4 | Uji statistik pre dan post-test

\begin{tabular}{cc}
\hline Uji & Paired t-test \\
\cline { 2 - 2 } & $p$-value \\
\hline Pre-post test & $<0,001$ \\
\hline
\end{tabular}

Dari Gambar 3, dari hasil analisa presentase tingkat pemahaman radiografer terhadap $\mathrm{DRL}$ dengan presentase responden jawaban pre-test yaitu 59\% dan presentase responden jawaban post-test $94 \%$. Kemudian dari Tabel 3. hasil uji peningkatan pemahaman radiografer sebagai upaya optimisasi berdasarkan uji statistik paired $t$ test $p$-value $<0,001$. Maka dipastikan radiografer mengalami peningkatan pemahaman setelah dilakukan sosialisasi tentang DRL sebagai upaya optimisasi. Hal ini 
diharapkan agar radiografer dapat menerapkan upaya optimisasi dalam melakukan pemeriksaan radiografi sesuai dengan nilai dosis yang direkomendasi oleh BAPETEN yang ditunjukan pada Tabel 5 .
Radiografer dapat menggunakan pengukuran radiation output (persamaan 3 ) sebagai panduan estimasi dosis radiasi pemeriksaan radiografi.

Tabel 5 | Panduan dosis radiasi pemeriksaan radiografi umum (BAPETEN, 2019)

\begin{tabular}{lccc}
\hline $\begin{array}{c}\text { Jenis } \\
\text { Pemeriksaan }\end{array}$ & $\begin{array}{c}\text { Pasien Bayi (0-4 } \\
\text { Tahun) }\end{array}$ & $\begin{array}{c}\text { Pasien Anak-anak (5-14 } \\
\text { Tahun) } \\
\text { Dosis permukaan kulit (mGy) }\end{array}$ & $\begin{array}{c}\text { Pasien Dewasa (> } \\
\text { 15Tahun) }\end{array}$ \\
\hline Chest AP & 0,4 & 0,5 & 0,6 \\
\hline Chest PA & 0,2 & 0,7 & 0,6 \\
\hline Upper extremities & & 0,7 & 0,4 \\
\hline Lower Extremities & & & 0,4 \\
\hline Abdomen AP & & 2,6 \\
\hline BNO AP & & 1,8 \\
\hline Pelvis AP & & 1,7 \\
\hline Skull PA & & 1,3 \\
\hline Skull LAT & & 1,3 \\
\hline Waters & & \\
\hline
\end{tabular}

Dari hasil peningkatan pemahamanan radiografer terhadap $\mathrm{DRL}$ diharapkan bahwa dalam melakukan tindakan pemeriksaan radiografi perlu upaya optimisasi kepada pasien, hal ini perlu disadari radiografer tentang menerapkan budaya keselamatan dan proteksi radiasi, dimana setiap tindakan pemeriksaan radiografi wajib mengupayakan pemberian paparan radiasi dan kualitas citra yang dihasilkan seoptimal mungkin. Perlu dipahami bahwa DRL bukan nilai yang menunjukan batasan dosis radiasi yang diterima oleh pasien, akan tetapi sebagai salah satu indikator mutu pelayanan radiologi, pasien dapat menerima paparan radiasi melebihi DRL, dengan didarai bahwa secara medis hal ini tidak dapat dihindari (BAPETEN, 2019).

\section{KESIMPULAN}

Dalam peningkatan pemahaman radiografer terhadap $\mathrm{DRL}$ sebagai upaya optimisasi pada pemeriksaan radiografi dengan pengukuran estimasi dosis radiasi metode radiation output dan sosialisasi terkait DRL, dengan keberhasilan peningkatan pemahaman pada post test $>90 \%$. Pada pengukuran dosis radiasi menggunakan metode radiation output dengan menentukan persamaan power function, dimana nilai laju dosis radiasi meningkat seiring meningkatnya nilai $k V p$ dengan $y=0.0005 x^{2.9242}$. Dari hasil pre test didapatkan jumlah jawaban yang benar dengan presentase yaitu 59\%. sedangkan untuk hasil post test jumlah jawaban yang benar yaitu presentase yaitu 94\%. Hasil uji peningkatan pemahaman radiografer sebagai upaya optimisasi berdasarkan uji statistik paired t-test p-value < 0,001 . Maka dipastikan radiografer mengalami peningkatan pemahaman setelah dilakukan sosialisasi tentang DRL sebagai upaya optimisasi pada pemeriksaan radiografi. 
DAFTAR PUSTAKA

BAPETEN. (2002). Peraturan Badan Pengawas Tenaga Nuklir Nomor 2 Tahun 2018 tentang Uji Kesesuaian Pesawat Sinar-X Radiologi Diagnostik dan Intervensional. Retrieved August 25, 2020, from https://jdih.bapeten.go.id/id/dokumen/per aturan/peraturan-badan-pengawastenaga-nuklir-nomor-2-tahun-2018tentang-uji-kesesuaian-pesawat-sinar- $x$ radiologi-diagnostik-dan-intervensional

BAPETEN. (2003). Keputusan Kepala Badan Pengawas Tenaga Nuklir Nomor 01P/Ka-BAPETEN/I-03 tentang Pedoman Dosis Pasien Radiodiagnostik. Retrieved August 25, 2020, from https://jdih.bapeten.go.id/id/dokumen/per aturan/keputusan-kepala-badanpengawas-tenaga-nuklir-nomor-01-pkabapeteni-03-tentang-pedoman-dosispasien-radiodiagnostik

BAPETEN. (2011). Perka BAPETEN Nomor 8 Tahun 2011 tentang Keselamatan Radiasi dalam Penggunaan Pesawat Sinar-X Radiologi Diagnostik dan Intervensional, 1-55.

BAPETEN. (2016). Pedoman Teknis Penyusunan Tingkat Panduan Diagnostik Atau Diagnostic Reference Level (DRL) Nasional, (8). https://doi.org/10.1039/C5RA02987B

BAPETEN. (2019). Pedoman Teknis Penyusunan Tingkat Panduan Diagnostik Atau Diagnostic Reference Level (DRL) Nasional. https://idrl.bapeten.go.id/assets/upload/p edkes_DRL.pdf

Don, S., Whiting, B. R., Rutz, L. J., \& Apgar, B. K. (2012). New exposure indicators for digital radiography simplified for radiologists and technologists. American Journal of Roentgenology. https://doi.org/10.2214/AJR.12.8678
Hastuti, P., Syafitri, I., Di, P. S., Radiologi, F., \& Definisi, D. (2009). Uji Kesesuaian Sebagai Aspek Penting Dalam Pengawasan Penggunaan Pesawat Sinar-X Diagnostik, 269-277.

Hiswara, E., \& Kartikasari, D. (2015). Dosis Pasien Pada Pemeriksaan Rutin Sinar-X Radiologi Diagnostik. Jurnal Sains Dan Teknologi Nuklir Indonesia, 16(2), 71. https://doi.org/10.17146/jstni.2015.16.2. 2359

IAEA. (2007). Dosimetry in diagnostic radiology: An international code of practice TRS 457. Technical Reports Series No. 475.

Irsal M, Guntur W. Pengaruh parameter Milliampere-Second (mAs) terhadap Kualitas Citra Dan Dosis Radiasi Pada Pemeriksaan Computed Tomography (CT) scan Kepala Pediatrik. J Fis Flux. 2020;17(1):1-8.

Muhammad, I., Hidayanto, E., \& Arifin, Z. (2014). Analisa Pengaruh Faktor Eksposi Terhadap Entrance Surface Air Kerma (Esak). Retrieved July 30, 2020, from https://www.researchgate.net/publication /339886790_Analisa_Pengaruh_Faktor_ Eksposi_Terhadap_Entrance_Surface_ Air_Kerma_Esak

Nations Scientific Committee on the Effects of Atomic Radiation, U. (2010). SOURCES AND EFFECTS OF IONIZING RADIATION United Nations Scientific Committee on the Effects of Atomic Radiation UNSCEAR 2008 Report Volume I: SOURCES Report to the General Assembly Scientific Annexes A and $B$ This publication contains: VOLUME I: SOURCES Report of the United Nations Scientific Committee on the Effects of Atomic Radiation to the General Assembly Scientific Annexes Annex A. Medical radiation exposures Annex B. Exposures of the public and 
workers from various sources of radiation.

Rochmayanti, D., Ardiyanto, J., \& Wibowo, A. S. (2016). Pelatihan pengaturan indeks eksposure untuk optimasi kualitas radiograf dan estimasi dosis pada computer adiografi kodak (studi klinis organ thoraks pulmonum dan abdomen). Link, 12(1), 15-19. Https://doi.org/10.31983/LINK.V12I1.420 Sriwahyuni, S. (2017). The PENGARUH TEGANGAN TABUNG (KV) TERHADAP KUALITAS CITRA RADIOGRAFI PESAWAT SINAR-X DIGITAL RADIOGRAPHY (DR) PADA PHANTOM ABDOMEN. SPEKTRA: Jurnal Fisika Dan Aplikasinya, 2(2), 113. https://doi.org/10.21009/spektra.022.04 